\title{
"To be HIV positive is not the end of the world": Resilience in perinatally infected HIV positive adolescents in Johannesburg
}

Background: Resilience, or positive adaptation to challenging situations, has potential to improve health outcomes for high risk populations. Resilience may be particularly important for perinatally infected HIV positive adolescents, who are exposed to significant stigma, risks and stressors. Despite recognition that HIV positive adolescents show remarkable resilience in the face of adversity, little is known about how resilience occurs within this population.

Methods: The aim of this study was to identify elements of resilience in a group of perinatally infected HIV positive adolescents attending HIV clinics. In-depth interviews were conducted with 25 purposively selected HIV positive adolescents (15 female, 10 male) between the ages of 13-19 years in Johannesburg. Data were analysed in NVIVO 10 using a thematic approach to coding.

Results: Despite marked stressors in the lives of these adolescents, a high degree of resilience was described. Characteristics of resilience in this group included a pertinent set of beliefs, including a belief in fate and recognition of personal strength as a consequence of managing adversity. Character traits such as a pragmatic acceptance about one's life, actively taking responsibility, and a robust self-esteem were evident. Social behaviours included the ability to pursue and access adults and healthcare to meet developmental needs, having a desire to support and help others and challenging HIV related stigma. These characteristics were underscored by the capacity for selfreflection.

Conclusion: Perinatally infected adolescents, who face high levels of hardship and change, nevertheless exhibit strong resiliency beliefs, traits, and behaviours. Healthcare environments have the potential to be utilized as powerful resources in fostering resilience in HIV positive adolescents if characteristics of adolescent resilience were integrated into current prevention and intervention programming. Resilience promotion could lead to improved health outcomes for HIV positive adolescents.

Keywords: resilience; perinatal HIV infection; HIV positive adolescents; healthcare system; orphan; vulnerable youth 


\section{"To be HIV positive is not the end of the world": Resilience amongst? perinatally infected HIV positive adolescents in Johannesburg}

\section{Introduction}

'Resilience' is a relatively novel and decidedly complex concept (Ungar, 2013; Cicchetti, 2010; Windle, 2011; Masten, 2014; Zolkoski \& Bullock, 2012). Although there are many different definitions of resilience, they are broadly similar and refer to the positive adaptation of people to difficult situations (Skovdal \& Daniel, 2012). Resilience in the context of the HIV epidemic among children and adolescents is important, as it is well known that HIV adds a significant burden to development and that those infected are likely to suffer increased mental health problems and psychosocial stress (Betancourt et al, 2013; Cluver et al, 2012; Li et al, 2008; Mutumba et al, 2015; Sherr \& Mueller, 2009; Pienaar et al, 2011).

Among perinatally infected adolescents, resilience may be a particularly important construct. There is a significant burden of HIV in adolescents with 2.1 million adolescents aged 10-19 years living with HIV globally (UNAIDS, 2013). These adolescents tend to experience enduring adversity (multiple losses and bereavement, numerous sickness and hospitalization, poor school attendance, increased poverty and exposure to violence, stigma and discrimination, disclosure challenges) as well as low levels of physical, psychological and social resources which puts them at risk for developing mental health problems (Mavhu et al, 2013; Bernays et al, 2014; Lowenthal et al, 2014). Perinatally infected adolescents are also more likely to struggle with adherence to treatment (Agwu \& Fairlie, 2013; Kacanek et al, 2015; Lowenthal et al, 2014; Cluver et al, 2015) and may engage in unsafe sexual activity (Agwu \& Fairlie, 2013; Cluver et al, 2011). They are similarly at higher risk of sexual coercion and peer pressure (Kim et al, 2014), increasing the risk of secondary transmission. Indeed, nearly one-sixth of all new HIV infections are in adolescents aged 15-19 years (UNICEF, 2013) making this age group the most vulnerable incident infection population in South Africa (Shisana et al, 2014). Mitigating risk by improving mental health outcomes, particularly resilience, would be in the public health interest but more research is required to understand this construct in this population.

Studies indicate that individual characteristics, resources, and competencies - including age, cognitive capacity, sense of purpose, and belief in a positive future - contribute to resilience; supportive and accepting environmental conditions help shape resilience by mitigating the negative effects of adversity (Amzel et al, 2013). Resilience in HIV-infected adolescents is also influenced by the complex interplay between individual-level factors, family-level factors such as caregiver well being or illness, institutional-level factors such as access and engagement with health services and education, and societal factors such as stigma (Amzel et al, 2013; Betancourt et al, 2011). In addition, literature regarding HIV orphans (of which many are perinatally infected) has explored factors that contribute to their unique vulnerabilities. These are often associated with coping with the illness or loss of a parent, compounded by associated stigma, trauma and bereavement, and financial hardship (Wood et al, 2006; Daniel et al, 2007, Collishaw et al 2015, Li et al, 2015).

Masten (2001) coined the term 'ordinary magic' to refer to resilience as something nurtured by everyday resources, common to individuals, families, communities and cultures. These 
conventional roots of resilience suggest that resilience is not rare and that active steps can be taken to develop and sustain resilience among young people who are placed at risk by ordinary and extraordinary hardship (Theron \& Theron, 2010).

Whilst progress has been made in identifying and managing risk factors for HIV positive children and adolescents, little is known about how HIV positive adolescents demonstrate resilience and how the healthcare environment can be utilized as an agent of resilience for young people. We conducted qualitative research to explore the views of HIV positive adolescents attending clinics in Johannesburg regarding resilience and mental health.

\section{Methods}

\section{Participants and procedures}

The study nested qualitative research into an observational adolescent study conducted in five HIV clinics serving adolescents in Johannesburg, South Africa. Three of the clinics were hospital based; one was a community health center and one a primary healthcare clinic. All adolescents were on treatment for HIV and most had been attending the clinics for many years. Most participants were presumed to be infected at birth and had all lived with HIV for as long as they remembered, but it is possible that a small proportion were infected through blood transfusion or rape in childhood, although there is little data documenting this.

This qualitative study was linked to a quantitative study $(n=343)$ that will be reported elsewhere. Participants for this analysis were recruited purposively by research counsellors familiar to the adolescent based on consent and willingness to engage in in-depth interviews. Research counsellors were trained in pediatric HIV and advanced counselling, and volunteered to participate in the research, engaging in principles of ethical research with minors. They received an additional 5 day training for this study as well as weekly debriefing and supervision throughout the course of data collection. Research counsellors who administered the questionnaire identified these participants based on their apparent high functioning (i.e. scoring moderate to low on standardized mental health measures) despite significant described adversity. High functioning adolescents were chosen because their resilience was being investigated, i.e. these participants' reported difficulties and adverse life experiences did not seem to be impacting negatively on their mental health functioning. Participants also reported experience of being disclosed to about their HIVstatus. Twenty-five adolescents between 13 -19yrs (mean 16yrs; 15 female) were interviewed for approximately 60 minutes each by the principal researcher of the study using a semi-structured interview guide when they visited the clinic for their regular appointment. The interviews were recorded with participant consent and conducted in English as all participants spoke English fluently.

Participants were given a pocket sized card with active referrals for services in their neighbourhood including counselling, legal and crisis resources. Upon completion of the interview, participants received reimbursement for travel; a snack; and a gift voucher for R50 (US \$4) at a local clothing retailer. These items were endorsed and recommended by the adolescent community advisory board (CAB) instituted for this research. 


\section{Ethics consideration}

The South African National Health Act states that 'for health research with minors ( $<18$ year olds), consent from a legal parent or guardian for research with children must be obtained' (Section 71, 2012). This sample was speculated to possibly not have legal guardians from whom to obtain consent. As such, the ethics committee of the University of the Witwatersrand advised approaching the court for permission to enroll participants in the study by obtaining a court order which was granted and led to full ethics clearance and permission to interview volunteers without parental or guardian consent (M130258). Where this was the case $(n=343)$ adolescents gave verbal assent and written consent to participate in the research, and all participation was sought on the basis of good clinical practice guidelines (Verma, 2013). Permission was also granted from Gauteng Provincial Department of Health, Johannesburg District Department of Health, and the research committees of facilities.

Confidentiality was maintained except where participants were at risk of significant harm, including being actively suicidal or currently experiencing abuse, in which case interviews were stopped and immediate referrals were made to child protection and health services in accordance with mandatory reporting legislation in South Africa (Children's Act, 2005). Seventeen participants were screened out of the quantitative sample for active suicidality and four participants reported historic rapes. Where prior abuse or rape was no longer occurring, referrals were made to support and counselling services.

\section{Data analysis}

All interviews were transcribed verbatim in English. All identifying information regarding the participant or clinic setting was removed and transcripts were saved by a file name with no personal identifiers. Data were managed in QSR NVivo 10, a qualitative analysis software package, constructing an analytical framework of broad codes by creating a 'start list' of possible themes and building upon the research questions. Each broad code, or wide thematic basket of ideas (Creswell, 2014), was applied to each transcript and 'fine codes' were developed using an inductive approach deriving meaning from the data itself rather than imposing pre-formed ideas (Hutchinson et al, 2010). To ensure intercoder agreement, fine codes were developed by 4 researchers competent in qualitative data analysis by printing out a full set of excerpts (from each data set) related to each code for each transcript and identifying sub-themes emerging from the data. Two researchers applied the thematic code to each transcript, a technique called 'double coding'. The findings were critiqued by the group to guarantee research findings, highlighted the reality of the transcripts rather than simply one researcher's view of the data. During analysis, we found that data did reach a point of saturation, which leads us to believe the sample size was sufficient.

\section{Findings}

Of the 25 adolescent interviewed, 15 were female. All had been disclosed to, and most had known their HIV status for many years. Four participants were not orphaned, 7 were single orphans and $14(56 \%)$ were double orphans. Three of the participants lived in a children's home, 13 participants 
(52\%) lived with extended family members, mainly grandmothers, and the remainder lived with biological parents.

\section{Beliefs underpinning resiliency}

A strong theme emerging from adolescent participants was the idea that their own belief systems set the stage for their ability to be resilient. Many participants demonstrated a belief in fate with a comfort in the conviction that one is on the path one should be:

'So you know they say God throws challenges at you to make you stronger; God does not throw things that He knows that you cannot handle? He throws things at you that He knows that you can handle...so that's what keeps me going and to me like that's what tells me everything happens for a reason. There is a reason it happened [becoming HIV positive] and cannot be changed now and if I want to continue to live, I have to take my tablets and all that...so that's what keeps me going' (male, 18yrs)

This quote highlights another central theme that emerged regarding the value of challenges in life as a measure of personal resilience and validation of coping ability:

'Yes and like in life, all the things that you face, once you face them, you might find out that you're the strongest person...stronger than the person sitting next to you' (male, 18yrs)

Many participants were orphaned, the loss of their parents being one of the most profound challenges facing their development. However, one participant highlighted this 'risk' enabled him to recognize his strengths in coping:

'Ja but there's an upside too. It teaches you well; without your parents you can learn about life on your own, make your mistakes, learn from your mistakes and soldier on. Many people complain 'I don't have a parent, okay nothing's going to go my way'; they have a negative attitude believing nothing is going to ever work out without their parents around. I always did things on my own and even if there were hard times, I made it through' (double orphan, male, 17yrs)

Another participant drew attention to the particular challenges perinatally infected HIV positive children and adolescents manage:

'I would say when they grow up [children infected at birth with HIV] they will be stronger than what they were because they know responsibilities and that stuff other kids don't have to deal with' (female, 16yrs)

\section{Character traits as internalised resiliency}

Several character traits were important for the resilience and coping of adolescents. Many of the respondents had a flexible and pragmatic acceptance about their lives which helped them cope with their realities: 
'I easily accept things as they are. I never look too deep into things that 'why did it have to happen now?' and ask myself unanswerable questions. I just accept things - 'ok my uncle has died life goes on, that's just how it is with me' (double orphan who recently lost uncle who was primary caregiver at the time, male 17yrs)

One young woman described how accepting her own parents' death was difficult, but something that she was compelled to "deal with":

'It was a bit harder [dealing with parents' death and consequent HIV disclosure] but as time goes by I was accepting that this is me so I have to deal with it' (female, 16yrs)

This pragmatism translated into understanding and accepting their HIV diagnosis with consequent improved management of the disease.

...you do have medication and treatment, there's no use [need] for you to die because you have these things. Why should you die from HIV...to be HIV is not the end of the world' (male, 17yrs).

The following participant was a double orphan, living in a children's home who had accepted many hard realities in his life, including his HIV status:

'A lot' of children come to me and say 'how do you deal with this?' [being HIV positive] and I say 'it is easy'. I ask them how they deal with their lives. I ask them 'okay if you are ill and then the doctor said to you take this medicine for this month, would you do it or wouldn't you do it?' and they say to me 'I will do it'. And then I ask them why and they say 'because I'd like to be well and healthy'. And then I say 'okay, I'd also like to be healthy. I'm taking my medication every day so that's no big deal about that' and then they say 'okay so it's not a big deal' (male, 16yrs).

Many respondents spoke openly about the need to take responsibility for one's life and health, indicating an internal locus of control which had a direct impact on improved health outcomes.

'They will have to face the reality [HIV positive adolescents]...at the end of the day you will be the one to be happy about your health, at least you will be doing something. What's going on with your health, inside and outside your body, is your own responsibility...ja' (male, 16yrs)

Most participants exhibited a robust self-esteem and were able to identify the need for this particularly in overcoming HIV stigma that is still rife in communities.

'It's like a natural thing; you have to learn how to be strong. Without your self-esteem, maybe, you know people come to you and say 'you are HIV, ag we don't want to play with you and so on'. You just say 'okay thank you for that word but I will not take it seriously' and then move on with your life. Forget about that a long time ago and move on and say 'okay I'm HIV positive. I've got friends who are HIV and I've got friends who are negative, so why 
should I worry about them? I don't care what they are or who they are'. So for me selfesteem plays a big role but as far as I'm concerned no one should come to me with negative words and so forth because I don't think I deserve it, ja, I don't think I deserve it and I don't think anybody deserves it' (male, 16yrs)

Participants reported experiences of rejection on account of being HIV positive and the need to actively manage discrimination. One young woman described her coping techniques for dealing with insults and misconceptions around HIV:

'I think they [HIV positive adolescents] need a positive self-esteem; tell themselves positive things every time. Whenever a person insults you or say something stupid about HIV while you're listening to that person you must tell yourself in your head 'ag, whatever...I'm the person' and keep your head forward just continue telling yourself you are this person and you are not going to be what they say out there' (female, 17yrs)

Being self-assured and accepting oneself were the basis of this self-esteem:

'Well a lot of people think or say that I'm ignorant, I'm cocky you know like, but I'm just a simple person who wants to enjoy life and that's just full of courage. Even though the situation might be suppressing [oppressive], there's always a positive at the end of the tunnel. So yeah, courage drives me to see positive in negative' (male, 18yrs)

In addition, many participants demonstrated self-reliance that was key to self-esteem:

'If you don't believe in yourself, who will? Some people might see you as crap but hey you're believing in you for yourself and you see yourself as the greatest guy on earth. Successful, living life the way you wanted to live life with a family, children and so forth and if you're going to keep degrading yourself then everybody is going to keep looking down on you. So take down that balcony that they keep looking down on you from and be on the balcony that everybody can look up to you' (male 17yrs)

Many respondents reported being considered in their problem-solving, noting that with enough thought, they could come to a solution to problems.

'Use your head and not your feelings' that's all I can say because our emotions always make us make the wrong decisions but when you use your head you can actually manoeuvre through things...turn the bad into an advantage for you' (male, 18yrs)

Most participants were goal oriented and had plans for their futures coupled with a conviction of their future success.

'In the future I have a good plan and I do my schoolwork and stuff. So I know that I'm going to live this good life' (male, 18yrs)

I've told myself this is not the end of the world, I can live. I can do anything that I want to be 
and I thought I would die. I would never be a tour manager. So I said 'no, I'm going to be a tour manager when I grow up' (female, 14yrs)

\section{Social behaviours as actioned resiliency}

While accepting and acknowledging the challenges in their lives, for example being orphaned, most participants reported actively pursuing and accessing adults and parental role models to meet their developmental needs and obtain support where they could, demonstrating agency in effectively utilizing resources available for their own gain.

'...everyone in life, every father, every mother, every stepdad, every stepmom, every grandmother is a father to me, is a mother to me so I don't regret that. I don't feel pain that I don't have a mother or father of my own because I've got so many mothers and fathers on earth...so l'm good' (male, 18yrs)

This participant highlights his ability to relate to others, being flexible in his worldview and accomodating to his circumstances:

'I randomly meet people every day so I get talking with the person and I just share 'okay if you were in this situation as I am and so forth what would you do?' and then they would share lives. I take it a bit of what they told me and put it into the way that I see things and that would eventually help me in my life' (male, 17yrs)

In addition to accessing adults, another participant emphasises the need for uptake of healthcare services that are widely available in the country:

'I would advise them [other HIV positive adolescents] and teach them about ARV's and that they still have a chance to live. Having HIV doesn't mean that they are going to die any time soon. It's just a virus and you can control it if you want to. You mustn't let it control you because there are doctors that give us ARV's for free' (male, 18yrs)

Many adolescents, who were accessing pediatric healthcare clinics regularly, saw these environments as particularly helpful in their lives:

'For me like, what works for me is to go to the clinic, get your meds and all that, you meet people there and sometimes it makes me feel that I'm not alone and all that. So ja, it didn't only happen to me, so ja' (male, 18yrs)

They also relied on the pediatric clinic staff they had come to know and trust over time:

'...well it' convenient number one [coming to one place regularly for support] and the people here they have a good attitude and have a mind of a kid which is very good. They know what a kid who is HIV is thinking, they're very supportive...they know what a kid has to go through to fight this kind of thing' (male, 17yrs) 
Interestingly, all participants had a strong desire to support and help others, especially young people struggling with their own HIV disease.

'I picture myself helping people who are HIV positive, encouraging them with their treatment, advising them not to give up with life, not to think that it's the end of the world, you know' (female, 18yrs)

Much of the help suggested tended to be around mentorship and factual information sharing regarding HIV infection, treatment and care, suggesting that many young people do not have accurate information about HIV disease or are deliberately told lies about their health.

Interviewer: So you feel it is your responsibility to educate other HIV positive teenagers?

Interviewee: Yes, so they can get proper information

Interviewer: Why? Why you?

Interviewee: I don't know, maybe it's because I know what it is like and I would love to tell them, so that they can know...not hear it from one who is telling them lies (female, 19yrs)

Being able to share their knowledge and expertise regarding HIV would likely be of benefit to peers experiencing similar realities and challenges.

'I would like to talk to other HIV positive teenagers about what it is like to live with HIV if they would like to listen and would like to be helped with getting information about HIV. We can fight this. We are lucky to have medication and together we can do more and give back to the community. We are not a bunch of losers' (male, 18yrs)

The following quote indicates that many vertically infected children and adolescents may not know how they contracted HIV and need to understand vertical transmission as well as the prevention of mother to child transmission (PMTCT) prevention interventions.

'I will teach them how did they get HIV from...If they never slept with anyone, so it happens maybe they got it from the mother' (female, 19yrs)

In terms of messages for other HIV positive and adolescents, this group had recommendations that are in line with national and international guidelines, suggesting that they may have internalized what they have been taught at the clinic and through support groups etc. including accepting one's status...:

'...accept your status and if you know how to work with it, you can have a good life...tell them it's all in the mind, you just have to change the way you think about taking treatment and it will work for you' (male, 18yrs)

...disclosing one's status: 
'it's not a good thing to hide the virus to the people you live with, so it's better to tell them' (male, 17yrs)

...and adhering to treatment:

'I will tell them 'drink your medication', don't be scared. Don't let other people break your heart, no matter what, never mind what people say about your status, your life is yours, it's not other people. Go to the clinic and fetch your medication' (female, 18yrs)

These recommendations were framed by challenging stigma around HIV where myths and negative beliefs still appear to be present amongst young people.

'I will tell them that people who have HIV they are also normal people that can do what the people who don't have HIV do...being HIV it's a very normal thing, you are not a loser. And people who don't have HIV they can learn from people who have HIV a lot of things' (male, 18yrs)

One participant alluded to the fact that stigma can be driven by lack of information, something he felt compelled to challenge:

'The one message I'd like to say to them, as South Africans, let us prove other countries wrong by taking our medication, starting to get very very low percentages of AIDS killing people in South Africa. I'd like to tell them that HIV is not a death sentence' (male, 16yrs)

\section{Discussion}

The aim of this study was to identify characteritics of resilience in a group of perinatally infected HIV positive adolescents attending clinics in Johannesburg for their HIV care and treatment. Features of resilience in this group were underscored by beliefs and character traits that enabled their ability to manage their adversity, as well as social behaviours that created the agency necessary for success. This study identified that stigma, both community stigma and self-stigma, are significant challenges that HIV positive adolescents are dealing with. Many studies that identify stigma as a challenge, also identify social support as protective against the risks associated with stigma (Betancourt et al 2013). Opportunities to increase social support or even just the perception of social support (Cluver et al 2009) can enhance resilience in young people.

This study testifies to participant's creativity and demonstrates their active role in negotiating access to care, strategically navigating through the social supports available to them, including that of the healthcare sector. Counter to narratives of tragedy and doom, for orphans in particular, this study supports others that have identified tactical agency employed by young people in conditions of heightened vulnerability (Vale \& Thabeng, 2015). Young people's agency and ability to steer through support networks is a key pathway to resilience (Skovdal \& Daniel, 2012) and should be encouraged and reinforced, particularly in HIV positive adolescents. 
The resilience characteristics highlighted among this adolescent sample are underlined by the capacity for self-reflection. Self-reflection is widely regarded as marking an unfolding developmental competence fully emerging in adolescence (Barkai \& Rappaport, 2011). Interestingly, stressful life events tend to promote self-reflection in resilient people, representing an adaptive psychosocial capacity preferentially engaged as a means to overcome adversity (Thorne et al, 2004). Self-reflection is highly indicative of resilience. Thus supportive adults, including healthcare providers who ask young patients about their meaningful life experiences (such as bereavement) may guide patients to insight and reflection which could bolster resilience.

Theories of resilience posit that individual resilience occurs when there is an opportunity structure (an environment that facilitates access to resources) and willingness by those who control resources to provide what individuals need in ways that are congruent with their values (Ungar, 2013). As such, these data suggest that the healthcare environment could benefit from being sufficiently youth friendly with professionals willing to serve the needs of the adolescents who attend for care and treatment (Tylee et al, 2007; Pettitt et al, 2013). In addition, efforts to increase the perception of facilities as valuable resources for youth would improve access to services and could increase youth resilience in currently untapped ways. Participants in this study highlighted the fact that they had engaged in healthcare for many years - perinatally infected youth typically access treatment throughout their development and come to know their providers well. Intrinsically, this environment and those who work in it, can be seen as protective. The healthcare sector could foster an increased agency in its young patients, with consequent positive impacts on treatment adherence and retention in care; supporting empowered patients with hope for the future. This will be critical to the self-management of HIV disease when the infected adolescents are transitioned into HIV adult care centers.

Messages of perseverance and hope were consistent with strong encouragement for continued and consistent adherence to medication and treatment. Adherence is a known challenge in adolescent care (Cluver et al, 2015; Lowenthal et al, 2014; Agwu \& Fairlie, 2013). Adolescents though have potential influence over their peers (Mavhu et al, 2013); acceptance and friendship are frequently moderators to adversity (Criss et al, 2002). As such, programmes that work with HIV positive adolescents may benefit from peer messaging at clinic level in the form of peer led support groups, peer treatment navigators/counsellors for young people (supported carefully and supervised by skilled facilitators), and inclusion of young HIV positive adolescents in the multidisciplinary team or on the clinic community advisory board etc. This inclusion improves HIV outcomes among adolescents (Van der Heijden \& Swartz, 2010; Pettitt et al, 2014; Mupambireyi et al, 2014) and most participants in this study were open and invested in supporting other HIV positive youth.

The participants shared being confronted by pervasive negative beliefs about HIV, perpetuating stigma, which they countered with phrases such as "HIV is not the end of the world", "you are not going to die soon", and "HIV is not a death sentence". Sensitization regarding HIV within adolescent communities may need improved efforts towards stigma reduction, with more accurate messaging regarding HIV disease and treatment, and especially, precise information about prevention methods such as PMTCT. Many young people, especially those perinatally infected, are dealing with personal losses of those who died of HIV (many of these deaths personally witnessed) which may lead to inaccurate and pervasive negative beliefs around the disease. In addition, it is 
likely that at the time of diagnosis for these adolescents, they were likely considered terminal (Small et al, 2014). These beliefs could translate to a fear of death at one's own disclosure signifying the need for a keen understanding of death as well as HIV treatment so that negative beliefs can be managed as they surface developmentally (Wood et al, 2006; Daniel et al, 2007). Negative beliefs are compounded by a 'culture of silence' surrounding death which serves to reinforce stigma; the antidote to this would be honest conversations with young people regarding HIV related death. Resilience must be framed within a personal struggle with bereavement that conceptually impacts on one's own understanding of HIV disease and its management. These participants felt that only with accurate and factual information on both death (developmental understanding of death as well as accurate information regarding the death of primary caregivers, including how HIV turned to AIDS related deaths) as well as HIV (vertical transmission, the benefits of treatment and the importance of adherence) can HIV positive adolescents be resilient in the face of their circumstances.

There is little doubt that HIV leads to experiences of anxiety and depression in children and adolescents, and a 'pathologizing' focus may serve an important purpose in highlighting the hardship experienced by children and adolescents leading to policies and programming to serve these needs. But it is crucial that such a focus does not overshadow the plurality of experiences of HIV infected and affected children and adolescents and the ability of some to deal successfully with significant hardship (Skovdal, 2012). While noting too that attention should be paid to the potential hidden costs of resilience, i.e. some young people pay a price for resilient functioning where resilience in one developmental phase or in one domain of functioning may exact concurrent or deferred tolls in another or mask distress (Theron, 2012); resilience is nonetheless evident, and gives clues to understanding agency, promoting health in ways that can serve young people positively.

There is no single path to resilience and although the participants of this study demonstrated resilience at the time of interview, studies do suggest that adolescents have varying levels of resilience at various times during their lives (Howard \& Dryden, 1999). Adolescents who seem resilient in one set of circumstances may suffer when other difficulties arise. This suggests that it is the interaction and accumulation of individual and environmental risk factors that contributes to both risk and resilience (Killian, 2004). If the healthcare environment can be seen and used as a resource to HIV positive adolescents, sustaining the positive effects of resilience lies within its area of influence and health care providers could be pivotal agents of resilience in their treatment and care of young people living with HIV. For perinatally infected HIV positive adolescents who endure many changes in their lives, their healthcare providers are often consistent and reliable resources - professionals with significant potential to foster resilience. Programmes that actively include some of the characteristics of resilience described in this study may powerfully impact their patients.

The findings from the study are limited in several ways. Firstly, the adolescents were purposively recruited from clinics based on their responses to a questionnaire and the view of the counsellor administering the tool, thus the sample may overrepresent resilience among a population that may, more typically, face major barriers to resilience and mental health. Secondly, there was no comparison group of adolescents who were not coping and thus potential significant differences in 
what made some adolescents more resilient than others could not be assessed. Thirdly, this was a clinic-based sample in an urban environment and it is likely that participants may not reflect the broader adolescent population - futher research is needed with rural adolescents and those not accessing healthcare. Lastly, it was not the intention of this study to analyse the concept of resilience but merely to describe resilient characteristics found in this particular population. $A$ relatively small number of participants were interviewed, yet given the dearth of research among this population in South Africa (in part due to research restrictions), the sample size was an important first step in characterising perinatally infected adolescents.

\section{Conclusion}

This study highlights how adolescents infected with HIV manage a range of risk factors and appear to have characteristics of resilience that enhance their ability to meet the challenges in their lives. Perinatally infected HIV positive adolescents are best-placed to define the outcome of resilience and their voices are underscored in this paper. Noting how adolescents cope can indicate elements of an effective response. Facilitating resilience in public health programming could have positive effects on mitigating risk for a vulnerable yet engaged population.

\section{Acknowledgements}

We thank the participants for sharing their stories. We also acknowledge the impressive work of the research counsellors (Thamsanqa Jabavu, Nombulelo Shezi, Linda Mazibuko, Princess Mbatha, Tebogo Moloi, Honey Nyapoli, Bafana Gxubane, Shanaaz Randeria and Relebohile Maleka) both in their capacity as counsellors, dealing with complicated psychosocial issues in their adolescent patients, and for their enthusiasm in engaging in this research. Thanks to Kirsten Thomson and Shenaaz Pahad for coding parts of the data and discussing results, and to Pirilani Banda for managing the administrative aspects of the research. We are grateful to the Department of Health for allowing access to the patients and facilities in Johannesburg as well as Adv. John Peter (SC) for willingly assisting in gaining a court order to conduct this research.

\section{References}

Agwu, A. L., \& Fairlie, L. (2013). Antiretroviral treatment, management challenges and outcomes in perinatally HIV-infected adolescents. Journal of the International AIDS Society, 16(1)

Amzel, A., Toska, E., Lovich, R., Widyono, M., Patel, T., Foti, C., \& Altschuler, J. ( 2013). Promoting a combination approach to paediatric HV psychosocial support. AIDS, 27, 147-157

Barkai, A.R. \& Rappaport, N. (2011). A psychiatric perspective on narratives of self-reflection in resilient adolescents. Adolescent Psychiatry, 1, 46-54

Bernays, S., Jarrett, P., Kranzer, K. \& Ferrand, R.A. (2014). Children growing up with HIV infection: the responsibility of success. Lancet, 383, 1355-57

Betancourt, T. S., Myers-Ohki, S. E., Charrow, A \& Hansen, N. (2013). Annual Research Review: 
Mental health and resilience in HIV/AIDS-affected children-a review of the literature and recommendations for future research. Journal of Child Psychology and Psychiatry, 54(4), 423-444

Betancourt, T.S., Meyers-Ohki, S., Stulac, S.N., Barrera, E., Mushashi, C. \& Bearslee, W. R. (2011). Nothing can defeat combined hands (Abashize hamwe ntakibananira): Protective processes and resilience in Rwandan children and families affected by HIV/AIDS. Social Science and Medicine, 73(5): 693-701

Cicchetti, D. (2010). Resilience under conditions of extreme stress: a multilevel perspective. World Psychiatry, 9(3), 145-154

Cluver, L., Gardener, F. \& Operario, D. (2007). Psychological distress amongst AIDS-orphaned children in urban South Africa. Journal of Child Psychology and Psychiatry, 48 (8), 755-763

Cluver, L., Fincham, D. S., \& Seedat, S. (2009). Posttraumatic stress in AIDS-orphaned children exposed to high levels of trauma: The protective role of perceived social support. Journal of Traumatic Stress, 22(2), 106

Cluver, L., Orkin, M., Boyes, M., Gardner, F. \& Meinck, F. (2011). Transactional sex amongst AIDSorphaned and AIDS-affected adolescents predicted by abuse and extreme poverty. Journal of Acquired Immune Deficiency Syndrome, 58: 336-343

Cluver, L., Orkin, M., Gardner, F. \& Boyes, M.E. (2012). Persisting mental health problems among AIDS orphaned children in South Africa. Journal of Child Psychology and Psychiatry, 1-8

Cluver, L. D., Hodes, R. J., Toska, E., Kidia, K. K., Orkin, F. M., Sherr, L., \& Meinck, F. (2015). 'HIV is like a tsotsi. ARVs are your guns': associations between HIV-disclosure and adherence to antiretroviral treatment among adolescents in South Africa. AIDS, 29, 57-65

Collishaw, S., Gardner, F., Lawrence Aber, J. \& Cluver, L. (2015). Predictors of mental health resilience in children who have been parentally bereaved by AIDS in urban South Africa. Journal of Abnormal Child Psychology, 1-12

Creswell, J.W. (2014). Research design: qualitative, quantitative and mixed methods approaches (4th Ed). Sage Publications: California, USA

Criss, M. M., Pettit, G. S., Bates, J. E., Dodge, K. A., \& Lapp, A. L. (2002). Family adversity, positive peer relationships, and children's externalizing behaviour: A longitudinal perspective on risk and resilience. Child Development, 73(4), 1220

Daniel, M., Malinga Aplla, H., BjØrgo, R., \& Therese Lie, G. (2007). Breaching cultural silence: enhancing resilience among Ugandan orphans. African Journal of AIDS Research, 6(2), 109-120

Gadow, K.D., Chernoff, M., Williams, P.L., Brouwers, P., Morse, E., Heston, J., Hodge, J., Di Poalo, V., Deygoo, N.S. \& Nachman, S. (2010). Co-occuring psychiatric symptoms in children perinatally 
infected with HIV and peer comparison sample. Journal of Developmental Behavioural Pediatrics, 31(2), 116-128

Gadow, K.D., Angelidou, K., Chernoff, M., Williams, P.L., Heston, J., Hodge, J. \& Nachman, S. (2012). Longitudinal study of emerging mental health concerns in youth perinatally infected with HIV and peer comparisons. Journal of Developmental Behavioral Pediatrics, 33(6), 456-468

Howard, S., Dryden, J., \& Johnson, B. (1999). Childhood resilience: Review and critique of literature. Oxford Review of Education, 25(3), 307-323

Hutchison A.J., Johnston, L.H. \& Breckon, J.D. (2010). Using QSR-NVivo to facilitate the development of a grounded theory project: an account of a worked example. International Journal Social Research Methodology, 13, 283-302

Kacanek, D., Angelidou, K., Williams, P.L., Chernoff, M., Gadow, K.D. \& Nachman, S. (2015). Psychiatric symptoms and antiretroviral nonadherence in US youth with perinatal HIV: a longitudinal study. AIDS, 29, 1227-1237

Killian, B. (2004). Risk and resilience. A generation at risk, in Pharoah, R. (ed) HIV/AIDS, vulnerable children and security in Southern Africa. Institute for Security Studies

Kim, S-H., Gerver, S.M., Fidler, S. \& Ward, H. (2014). Adherence to antiretroviral therapy in adolescents living with HIV: systematic review and meta-analysis. AIDS, 28, 1945-1956

Li, X., Chi, P., Sherr, L., Cluver, L. \& Stanton, B. (2015). Psychological resilience among children affected by parental HIV/AIDS: a conceptual framework. Health Psychology and Behavioral Medicine, 3(1), 217-235

Li, X., Naar-King, S., Barnett, D., Stanton, B., Fang, X. \& Thurston, C. (2008). A developmental psychopathology framework of the psychosocial needs of children orphaned by HIV. Journal Association Nurses AIDS Care, 19(2), 147-157

Lowenthal, E.D., Bakeera-Kitaka, S., Marukutira, T., Chapman, J., Goldrath, K. \& Ferrand, R.A. (2014). Perinatally acquired HIV infection in adolescents from sub-Saharan Africa: a review of emerging challenges. Lancet Infectious Disease, 14(7), 627-639

Masten, A. S. (2014). Global perspectives on resilience in children and youth. Child Development, 85(1), 6-20

Masten, A. S. (2001). Ordinary magic: Resilience processes in development. American Psychologist, 56(3), 227

Mavhu, W., Berwick, J., Chirawu, P., Makamba, M., Copas, A., Dariwo, J., Willis, N., Araya, R., Abas, M.A., Corbett, E.L., Mungofa, S., Layer, S.M. \& Cowan, F.M. (2013). Enhancing psychosocial support for HIV positive adolescents in Harare, Zimbabwe. PLOS ONE 8(7), 1-9 
Mellins, C.A. \& Malee, K.M. (2013). Understanding the mental health of youth living with perinatal HIV infection: lessons learned and current challenges. Journal of the International AIDS Society, 16, $1-19$

Mupambireyi, Z., Bernays, S., Bwakura-Dangarembizi, M., \& Cowan, F. M. (2014). "I don't feel shy because I will be among others who are just like me...": The role of support groups for children perinatally infected with HIV in Zimbabwe. Children and Youth Services Review, 45, 116-113

Mutumba, M., Bauermeister, J.A., Musiime, V., Byaruhanga, J., Francis, K., Snow, R.C. \& Tsai, A.C. (2015). Psychosocial challenges and strategies for coping with HIV among adolescents in Uganda: A qualitative study. AIDS Patient Care and STDs, 29(2), 86-94

Pettitt, E. D, Greifinger, R. C., Phelps, B. R., \& Bowsky, S. J. (2014). Improving health services for adolescents living with HIV in Sub-Saharan Africa: a multi-country assessment: original research article. African Journal of Reproductive Health: Special Edition on HIV/AIDS (4), 17, 17- 31

Pienaar, A., Swanepoel, Z., Van Rensburg, H., \& Heunis, C. (2011). A qualitative exploration of resilience in pre-adolescent AIDS orphans living in a residential care facility. Journal of Social Aspects of HIV/AIDS Research Alliance, 8(3), 128-137

Shisana, O, Rehle, T, Simbayi LC, Zuma, K, Jooste, S, Zungu N, Labadarios, D, Onoya, D et al. (2014) South African National HIV Prevalence, Incidence and Behaviour Survey, 2012. Cape Town, HSRC Press

Skovdal, M. (2012). Pathologising healthy children? A review of the literature exploring the mental health of HIV-affected children in sub-Saharan Africa. Transcultural Psychiatry, 49(3-4), 461-491

Skovdal, M., \& Daniel, M. (2012). Resilience through participation and coping-enabling social environments: the case of HIV-affected children in sub-Saharan Africa. African Journal of AIDS Research, 11(3), 153-164

Sherr, L. \& Mueller, J. (2009). Where is the evidence base? Mental health issues surrounding bereavement and HIV in children. Journal of Public Mental Health, 7(4), 31-39

Small, L., Mercado, M., Gopalan, P., Pardo, G., Mellins, C. \& McKay, M., M. (2014). Enhancing the emotional wellbeing of perinatally HIV infected youth across global contexts. Global Social Welfare, 1(1), 25-35

South African Children's Act 38 of 2005

Theron, L. C. (2012). Resilience research with South African youth: caveats and ethical complexities. South African Journal of Psychology, 42(3), 333-345 
Theron, L. C., \& Theron, A. M. (2010). A critical review of studies of South African youth resilience, 1990-2008: review article. South African Journal of Science, 106(78), 1-8

Thorne, A., McLean, K.C. \& Lawrence, A.M. (2004). When remembering is not enough: reflecting on self-defining memories in late adolescence. Journal of Personality, 72(3), 1-27

Tylee, A., Hailer, 0. M., Graham, T., Churchill, R., \& Sanci, L. A. (2007). Youth-friendly primary-care services: how are we doing and what more needs to be done? Lancet, 369(9572), 1565-1573

UNAIDS (2013). Global Report: UNAIDS Report on the Global AIDS Epidemic, 2013. Geneva.

Ungar, M. (2013). Resilience, trauma, context, and culture. Trauma, Violence \& Abuse, 14(3), 255266

UNICEF (2013). Towards and AIDS-free generation: Sixth stocktaking report. Geneva

Vale, B. \& Thabeng, M. (2015). Mobilising AIDS(S)? Contesting HIV as a social and economic resource among youth in South Africa's Eastern Cape. Journal of Southern African Studies, 41(4), 117

Van der Heijden, I., \& Swartz, S. (2010). Bereavement, silence and culture within a peer-led HIV/AIDS-prevention strategy for vulnerable children in South Africa. African Journal of AIDS Research, 9(1), 41-50.

Verma, K. (2013). Base of a research: good clinical practice in clinical trials. Journal of Clinical Trials, 3(1), 100-128

Windle, G. (2011). What is resilience? A review and concept analysis. Reviews in Clinical Gerontology, 21(2), 152-169

Wood, K., Chase, E. \& Aggleton, P. (2006). 'Telling the truth is the best thing': Teenage orphans'experiences of parental AIDS-related illness and bereavement in Zimbabwe. Social Science \& Medicine, 62, 1923-33

Zolkoski, S. M., \& Bullock, L. M. (2012). Resilience in children and youth: A review. Children and Youth Services Review, 34(12), 2295-2303 